\title{
AVALIAÇÃO DA RIQUEZA DE ESPÉCIES ARBÓREAS ATRAVÉS DOS MÉTODOS BOOTSTRAP E REGRESSAO QUADRÁTICA DE PLATÔ
}

\author{
EVALUATION OF WEALTH OF WATER SPECIES THROUGH BOOTSTRAP METHODS AND \\ QUATRATIC PLATO RETURN
}

\author{
Amanda Pereira Santos ${ }^{1}$, Luciano Cavalcante de Jesus França², Cássio Augusto Ussi Monti ${ }^{3}$, \\ Talles Hudson Souza Lacerda ${ }^{4}$, Kalill José Viana da Páscoa ${ }^{5}$, Lucas Rezende Gomide 6 \\ 1, 2, 3, 4, 5 Universidade Federal de Lavras, Lavras, Minas Gerais, Brasil-aman_daps@hotmail.com, \\ lucianodejesus@florestal.eng.br, cassioaumonti@yahoo.com,lacerdaths@hotmail.com, \\ kalillpascoa@gmail.com\&lucasgomide@ufla.br
}

RESUMO

As florestas tropicais no Brasil apresentam elevada diversidade de espécies arbóreas e, vêm sofrendo grande pressão devido a expansão agrícola, pecuária e outras atividades econômicas antrópicas. Diante desses fatores torna-se cada vez mais importante estudos fitossociológicos que envolvam riqueza de espécies, com intuito de conhecer o potencial biológico existente, bem como justificar a conservação dos remanescentes florestais nativos. Sendo assim, o objetivo deste trabalho foi verificar a suficiência amostral necessária para a quantificação da riqueza arbórea da Bacia Hidrográfica do Rio Grande (BHRG), no sul de Minas Gerais, avaliando em nível de fragmentos (parcelas por fragmento) e para toda a área da bacia (fragmentos na área total), essa análise foi estendida para a análise pontual da fitofisionomia Floresta Estacional Semidecidual, que é a principal fisionomia de ocorrência na bacia hidrográfica, verificando também a utilização da modelagem para a estimativa total de espécies arbóreas. 0 método utilizado foi a regressão de platô, para isso utilizou-se a reamostragem bootstrap sem reposição para a retirada da subjetividade na entrada dos dados no ajuste do modelo. A regressão de platô indicou o ponto onde seria encontrada a suficiência amostral. Concluiu-se, pelo modelo quadrático de resposta em platô, que a amostragem realizada para a bacia como um todo atingiu a suficiência amostral com 26 fragmentos. Já a nível de fragmentos, a suficiência amostral foi atingida em $55 \%$ dos fragmentos amostrados. Os resultados aqui apresentados podem ser utilizados para fins de indicação de espécies destinadas à recuperação de ecossistemas degradados, dentre outras aplicações de conservação florestal.

PALAVRAS-CHAVE: Amostragem, Análise de regressão, Diversidade, Manejo florestal.

\begin{abstract}
Tropical forests in Brazil have a high diversity of tree species and have been under great pressure due to agricultural expansion, livestock and other anthropic economic activities. Given these factors, phytosociological studies involving species richness are becoming increasingly important in order to know the existing biological potential, as well as justify the conservation of native forest remnants. Thus, the objective of this study was to verify the sufficiency of samples needed to quantify the tree richness of the Rio Grande River Basin (BHRG), in southern Minas Gerais, by assessing the level of fragments (plots per fragment) and for the whole area. of the basin (fragments in the total area), this analysis was extended to the punctual analysis of the Phytophysiognomy Semideciduous Seasonal Forest, which is the main physiognomy of occurrence in the watershed, also verifying the use of modeling for the total estimation of tree species. The method used was plateau regression, for this we used bootstrap resampling without replacement for the removal of subjectivity in data entry in the model adjustment. Plateau regression indicated the point where sample sufficiency would be found. It was concluded by the quadratic plateau response model that the sampling performed for the basin as a whole reached the sample sufficiency with 26 fragments. At the fragment level, sample sufficiency was achieved in 55\% of the sampled fragments. The results presented here can be used for the purpose of indicating species destined for the recovery of degraded ecosystems, among other forest conservation applications.
\end{abstract}

KEY WORDS: Sampling, Regression analysis, Diversity, Forest management. 


\section{INTRODUÇÃO}

As florestas tropicais mantem os mais altos níveis de biodiversidade do planeta (URQUHART, 2019), com destaque para o Brasil, que possui a flora arbórea mais diversificada do mundo (LORENZI, 2009), com uma estimativa de 55 mil espécies vegetais (BRACK et al., 2007). O Estado de Minas Gerais por sua vez é o que mais possui a maior variação de formações vegetais do Brasil, devido suas condições climáticas, geológicas e topográficas (REIS et al., 2007), o que garante ao estado grande diversidade de espécies nativas (OLIVEIRA FILHO \& SCOLFORO, 2008; SILVA et al., 2016).

Um exemplo a ser destacado, é a Bacia Hidrográfica do Rio Grande (BHRG), localizada ao longo das regiões sul e oeste de Minas Gerais, devido a sua grande extensão territorial $\left(143.437,79 \mathrm{~km}^{2}\right)$ apresenta grande diversidade de ecossistemas, variando desde o Cerrado até áreas da Mata Atlântica.

Nesse ambiente ecológico diverso, as florestas tropicais ainda sofrem distúrbios antrópicos como a fragmentação, que mudam sua estrutura vegetacional, principalmente devido à expansão agrícola e pecuária. Por sua vez, os remanescentes florestais existentes estão restritos às áreas onde a agricultura não se instalou, seja por limitações a mecanização, como topos de morros e áreas com declividade acentuada, ou por limitações legais como nas áreas de preservação ambiental, ou mesmo em unidades de conservação (MORENO et al., 2003; DIAS NETO et al., 2009; SAPORETTI JUNIOR et al., 2017).

A análise dos fragmentos florestais remanescentes é fundamental para a conservação da biodiversidade, sendo os estudos florísticos capazes de conhecer as diferenças entre as fitofisionomias das regiões e a ecologia das espécies presentes (CONDÉ \& TONINI, 2013), identificando ainda o potencial ecológico e econômico das florestas, justificando assim a necessidade da sua preservação.

O ponto inicial desses estudos é a aplicação dos métodos de amostragem, por meio dos inventários florestais, onde são obtidas informações qualitativas e quantitativas presentes em cada área de interesse, sobre os recursos florestais existentes, como: a composição florística, a estrutura da floresta, seus valores econômicos e ecológicos (BONETES, 2003; SOUZA et al., 2006; FRANCEZ et al., 2007).

O inventário florestal pode ser realizado pelo método de censo, em que todos os indivíduos da população de estudo são medidos, ou por amostragem, na qual é realizado uma amostragem na área de estudo e estima-se as variáveis de interesse para o restante da área. O primeiro caso, geralmente, não é utilizado em florestas nativas ou em grandes áreas, devido ao seu alto custo e tempo necessário para a realização (AUGUSTYNCZIK et al., 2013), sendo exceção nos planos de manejo florestal na Amazônia. Contudo, a amostragem é perfeitamente aplicável e, pode ser realizada utilizando diversos métodos e processos, que devem ser escolhidos conforme a área de estudo. Logo, deve-se conciliar sempre o objetivo pretendido, o custo aceitável e a precisão das informações (MEUNIER et al., 2001).

O sucesso na precisão do inventário florestal está diretamente associado em garantir que a amostra seja representativa da área total. Isso consiste na definição da área mínima necessária para representar a área de estudo, considerando a relação entre o esforço realizado para aumentar a área amostral e a informação adicional obtida com esse aumento, esse conceito é conhecido como suficiência amostral (DIONISIO et al., 2016).

No caso da definição da riqueza arbórea considera-se que a amostra atingiu a suficiência amostral, quando ocorre uma estabilização no número de espécies encontradas com o aumento no número de parcelas (patamar). No entanto, em florestas tropicais esse patamar dificilmente é encontrado, pois a diversidade de espécies nessas regiões é elevada, sendo que quanto maior o esforço amostral, mais espécies serão registradas (SCHILLING \& BATISTA, 2008).

Portanto, o que muitos pesquisadores fazem na prática é definir de forma arbitrária um tamanho amostral que se julgue adequado (MORO \& MARTINS, 2011). Para contornar esse problema, diversos métodos foram desenvolvidos, entre eles destacam-se o método da curva espécie-área ou curva de acumulação e a regressão em Platô (REIS et al., 2007).

A regressão de Platô é um método onde modela-se o comportamento da curva de acumulação de espécies por área, entre o ponto de origem e o platô, a segmentação nesse ponto forma um bissegmento (SILVA et al., 2008).

Nesse contexto, o objetivo do presente trabalho foi verificar a suficiência amostral necessária para a quantificação da riqueza arbórea na Bacia Hidrográfica do Rio Grande (BHRG), avaliando no primeiro momento em nível de fragmentos e posteriormente, para toda a área da bacia, utilizando a modelagem para a estimativa total de espécies arbóreas pelo método da regressão de Platô.

\section{MATERIAL E MÉTODOS}

\section{Área de estudo}


A Bacia Hidrográfica do Rio Grande (BHRG) está localizada na região sudeste do Brasil (Figura 1). Seu curso principal possui $1.360 \mathrm{Km}$, desde a sua nascente em Bocaína de Minas na Serra da Mantiqueira, até o encontro com o Rio Paranaíba, que acontece no município de Carneirinho (divisa com os estados de São Paulo, Mato Grosso do Sul e Goiás). A classe de solos predominante é Latossolo, solos profundos, com boas propriedades físicas e baixa fertilidade natural. Além disso, são encontradas na Bacia manchas expressivas de Neossolos litólicos (próximo ao curso do Rio Grande) e Argissolos (região centro-oeste).

Segundo a classificação climática de Thornthwaite (1955) (lu), o clima da Bacia pode ser dividido em quatro classes, sendo elas: Úmido B2 presente ao leste da Bacia (temperatura média de $20^{\circ} \mathrm{C}$ e precipitação de $1.500 \mathrm{~mm}$ ); Superúmido (temperatura média de $14^{\circ} \mathrm{C}$ e precipitação de $1.750 \mathrm{~mm}$ ) e Úmido B4 (umidade elevada com temperaturas mais baixas e uma precipitação superior a $1.700 \mathrm{~mm}$ ) na região da Serra da e o Úmido B3 (precipitação anual superior a $1.600 \mathrm{~mm}$ e temperatura média anual inferior a $18^{\circ} \mathrm{C}$ ) na região central da bacia.

A topografia da bacia é classificada como ondulada, com $57,2 \%$ da área apresentando declives superiores a 15\% (OLIVEIRA et al., 2019).

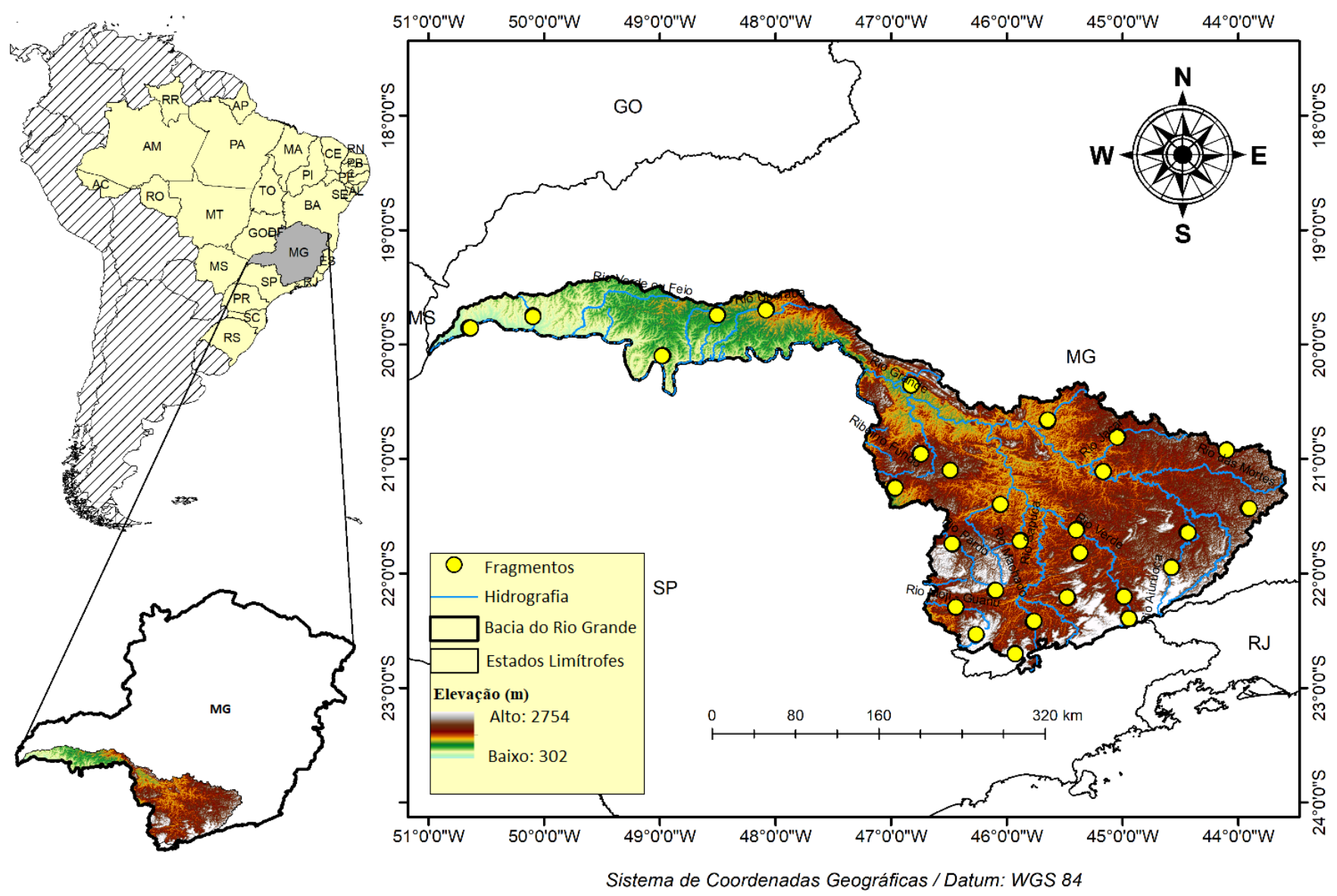

Figura 1. Mapa de localização da bacia hidrográfica do rio Grande (BHRG), Minas Gerais, Brasil, com representação de 29 pontos de fragmentos amostrados na área.

\section{Amostragem}

A BHRG foi estratificada em quatro grandes grupos, com base no zoneamento climático. Em cada grupo foi realizada uma subdivisão de acordo com a altitude (Tabela 1). Após a definição dos grupos, foram feitas as seleções das áreas amostrais, realizando uma cobertura sobre toda a Bacia. Essa seleção seguiu alguns critérios, sendo eles: a)
Respeitar os limites de cada grupo; b) Localização próxima aos cursos d'água e APP; e c) Amostrar 30 unidades amostrais ou 10 conglomerados.

Os fragmentos selecionados e suas localizações são apresentados na Figura 1 e Tabela 2. A amostragem escolhida foi em conglomerados, escolhida como forma de reduzir os custos de deslocamento. 
Tabela 1. Estratificação da BHRG de acordo com o zoneamento climático.

\begin{tabular}{cccc}
\hline \multirow{2}{*}{ Tipos climáticos } & \multicolumn{3}{c}{ Classes de altitude $(\mathrm{m})$} \\
\cline { 2 - 4 } & $\mathrm{I}$ & II & III \\
\hline Úmido B2 & $290-533$ & $533-776$ & $776-1.020$ \\
Úmido B3 & $618-818$ & $818-1.018$ & $1.018-1.218$ \\
Úmido B4 & $820-1.146$ & $1.146-1.472$ & $1.472-1.800$ \\
Superúmido & $980-1.420$ & $1.420-1.860$ & $1.860-2.300$ \\
\hline
\end{tabular}

Fonte: CEMIG (2014).

Tabela 2. Fragmentos (F), no munícipio, tipo fisionômico presente (TF), área do fragmento, com o número de parcelas (P), número de espécies observadas (S), número de árvores em cada fragmento (N), altitude (A), umidade (U) e tipo de solo (TS).

\begin{tabular}{|c|c|c|c|c|c|c|c|c|c|}
\hline $\mathbf{F}$ & Munícipios (MG) & TF & Área(ha) & $\mathbf{P}$ & $S$ & $\mathbf{N}$ & $A(m)$ & $\mathbf{U}$ & TS \\
\hline 1 & Nepomuceno & SE & 37,7 & 56 & 165 & 1.837 & 810 & Úmido B3 & Arg. \\
\hline 2 & Formiga & SE & 113,3 & 50 & 186 & 1.991 & 810 & Úmido B2 & Arg. \\
\hline 3 & Lagoa Dourada & SE & 57,8 & 47 & 188 & 1.779 & 1.130 & Úmido B3 & Camb. \\
\hline 4 & São Francisco de Paula & SE & 118,5 & 48 & 159 & 2.342 & 880 & Úmido B3 & Lato. \\
\hline 5 & Ibertioga & SE & 35,2 & 38 & 156 & 2.517 & 1.120 & Úmido B3 & Lato. \\
\hline 6 & Aiuruoca & SE & 123,1 & 42 & 147 & 1.839 & 1.050 & Úmido B3 & Neo. Lit. \\
\hline 7 & Varginha & SE & 65,7 & 45 & 172 & 1.707 & 860 & Úmido B3 & Lato. \\
\hline 8 & Campanha & SE & 39,4 & 41 & 152 & 1.559 & 940 & Úmido B3 & Lato. \\
\hline 9 & Pouso Alto & SE & 35,0 & 39 & 140 & 1.222 & 915 & Úmido B3 & Lato. \\
\hline 10 & Passa Quatro & SE & 37,1 & 27 & 134 & 1.805 & 1.150 & Úmido B4 & Lato. \\
\hline 11 & Gonçalves & OM & 37,3 & 32 & 69 & 1.854 & 1.700 & Superúmido & Lato. \\
\hline 12 & Machado & SE & 40,1 & 29 & 123 & 860 & 880 & Úmido B3 & Lato. \\
\hline 13 & Congonhal & SE & 26,7 & 29 & 117 & 925 & 890 & Úmido B3 & Lato. \\
\hline 14 & Conceição dos Ouros & SE & 44,3 & 28 & 130 & 749 & 880 & Úmido B3 & Lato. \\
\hline 15 & Pedralva & SE & 48,2 & 29 & 108 & 1.076 & 1.080 & Úmido B4 & Lato. \\
\hline 16 & Senador Amaral & SE & 33,6 & 38 & 152 & 1.740 & 1.440 & Superúmido & Lato. \\
\hline 17 & Ouro Fino & SE & 15,9 & 30 & 82 & 991 & 920 & Úmido B3 & Lato. \\
\hline 18 & Poços de Caldas & SE & 21,4 & 29 & 132 & 705 & 1.020 & Úmido B3 & Lato. \\
\hline 19 & Areado & SE & 17,9 & 28 & 96 & 625 & 820 & Úmido B3 & Lato. \\
\hline 20 & Nova Resende & SE & 23,8 & 29 & 136 & 1.380 & 1.110 & Úmido B3 & Lato. \\
\hline 21 & Monte Santo de Minas & SE & 107,3 & 29 & 130 & 887 & 690 & Úmido B3 & Lato. \\
\hline 22 & Fortaleza de Minas & SE & 86,5 & 30 & 141 & 1.330 & 1.090 & Úmido B2 & Arg. \\
\hline 23 & Delfinópolis & SE & 27,8 & 30 & 129 & 1.359 & 700 & Úmido B2 & Lato. \\
\hline 24 & Uberaba & SE & 67,6 & 30 & 140 & 836 & 680 & Úmido B2 & Lato. \\
\hline 25 & Campo Florido & CE & 32,6 & 33 & 101 & 1.531 & 650 & Úmido B2 & Lato. \\
\hline 26 & Frutal & CE & 70,4 & 27 & 48 & 568 & 500 & Úmido B2 & Lato. \\
\hline 27 & Iturama & CE & 60,3 & 33 & 73 & 1.245 & 410 & Úmido B2 & Lato. \\
\hline 28 & Carneirinho & CE & 179,5 & 32 & 69 & 942 & 370 & Úmido B2 & Lato. \\
\hline 29 & São Vicente & SE & 80,1 & 30 & 105 & 1.126 & 682 & Úmido B2 & Lato. \\
\hline Total & -- & -- & -- & 1.008 & -- & 39.327 & -- & -- & -- \\
\hline
\end{tabular}

Nota: Os tipos fisionômicos apresentados são floresta Estacional Semidecidual (SE), floresta Ombrófila (OM) e Cerradão (CE) e os tipos solos apresentados são Argissolo (Arg.), Latossolo (Lato.), Cambissolo (Cam) e Neossolo Litico (Neo. Lit).

A Figura 2 exemplifica essa distribuição, onde considera-se os vértices iniciais do primeiro elemento e o final do terceiro elemento totalizando em uma distância de $75 \mathrm{~m}$ entre os vértices dos três elementos. 


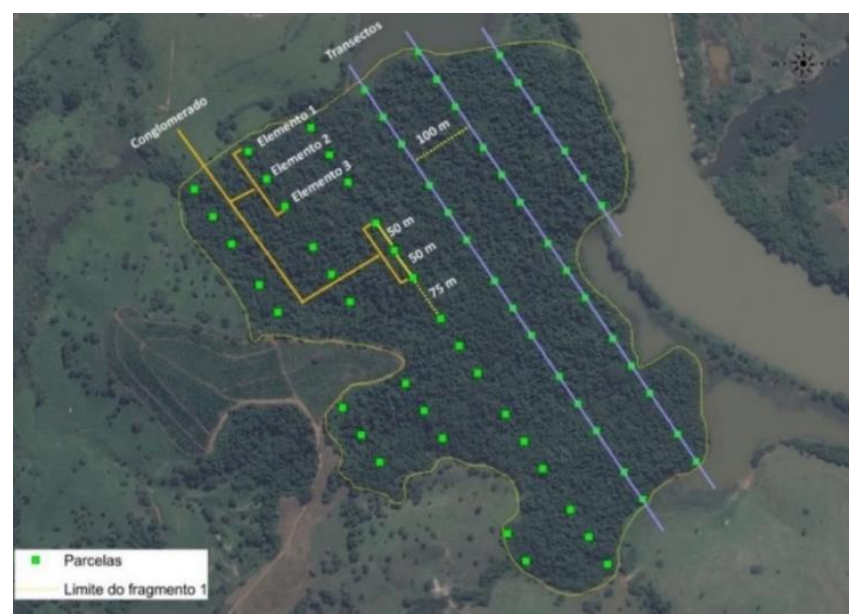

Figura 2. Modelo de lançamento dos fragmentos na BHRG. Fonte: CEMIG (2014).

As unidades amostrais foram sistematizadas na área e cada uma delas foi formada por um grupo de parcelas, onde os transectos foram instalados a uma distância de $100 \mathrm{~m}$ um dos outros ao longo de cada fragmento. Após os transectos foram lançados os conglomerados, que estavam distantes $50 \mathrm{~m}$ um do outro, contendo três elementos de $250 \mathrm{~m}^{2}$ (10 m x $\left.25 \mathrm{~m}\right)$, com uma distância de $25 \mathrm{~m}$ entre si (Figura 2).

Em cada fragmento, foram mensurados os indivíduos arbóreos com circunferência a altura de 1,3 m (CAP) acima de $15,7 \mathrm{~cm}$, a altura total e realizada a identificação botânica.

\section{Quantificação da suficiência amostral}

A cada espécie identificada foi atribuído um código diferente, que foi utilizado na estruturação da base de dados. Assim, na quantificação da suficiência amostral optou-se pelo método envolvendo a regressão linear quadrática de platô, sendo ajustado para cada fragmento e para toda a bacia. Esse modelo identifica o ponto em que a curva de suficiência amostral se estabiliza e forma o platô.

A Regressão de Platô, modela o comportamento da curva entre o ponto de origem e o platô, nesse método podem ser ajustadas várias equações, conforme a observação dos dados (FERREIRA, 2013). A segmentação acontece em um único ponto, proporcionando a formação de um bissegmento (SILVA et al., 2008). A primeira parte do segmento é uma reta crescente até uma determinada ordenada onde se forma o platô e a partir desse ponto acontece a segunda parte, onde se assume o valor constante, sendo que o platô é desconhecido e estimado juntamente com os outros parâmetros do modelo. De posse do modelo deduzido tem-se a possibilidade análise da suficiência amostral de uma amostragem realizada.

Como exemplo, tem-se o modelo utilizado na sua forma quadrática (Eq.1). A interpretação indica que para valores de $X<X_{0}, Y_{i}$ será explicado pela parábola (modelo quadrático) e para valores de $X>X_{0}$, a equação será constante e paralela à abscissa, já que esse tipo de modelo é segmentado. $O$ ponto $X_{0}$, que representa a junção entre o segmento quadrático e o platô, é desconhecido e estimado juntamente com os outros parâmetros do modelo. As duas curvas geradas (segmento quadrático e platô) devem ser contínuas (se encontrando no $X_{0}$ ) e suavizada, ou seja, as primeiras derivadas com relação ao $X$ devem ser a mesma no ponto $X_{0}$.

Na Figura 3 é possível visualizar uma curva gerada pelo modelo escolhido.

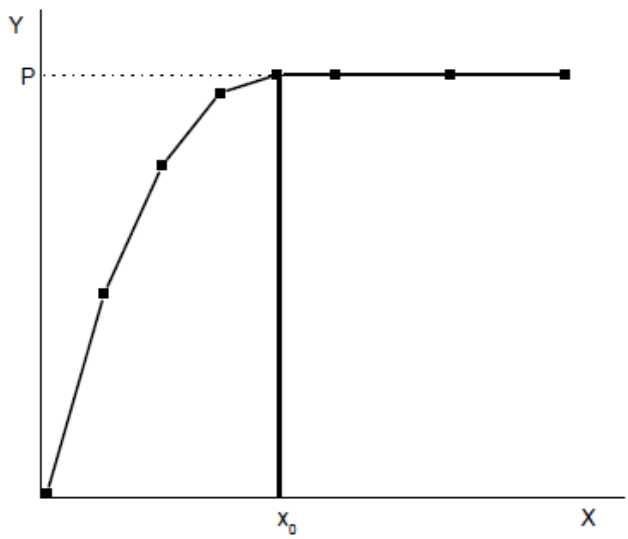

Figura 1. Representação gráfica do comportamento da curva e do platô.

Com o intuito de retirar-se a tendenciosidade na entrada dos dados no modelo de platô, a fim de não haver modificações propositais no comportamento da curva, realizou-se um sorteio com 100 repetições, envolvendo uma reamostragem sem reposição, utilizando o método de bootstrap. Em cada repetição desse sorteio, foi calculada a quantidade de espécies acumuladas por uma determinada área amostrada, sendo essa área acumulada progressivamente. O sorteio realizado demonstra como resultado três matrizes de saída, a primeira delas é binária e marca a presença/ausência das espécies. Essa matriz permitiu que espécies novas fossem contabilizadas com o aumento da área amostral.

A segunda matriz constava a ordem das parcelas selecionadas nos sorteios, já a terceira e última matriz, fornecia a frequência acumulada de espécies em cada parcela por sorteio. Ao final, obteve-se a média aritmética dessa variável.

A Figura 4 representa as três saídas geradas pelo 
método boostrap. A partir da segunda matriz gerada pelo sorteio, obteve-se duas variáveis para a entrada no modelo de platô. Para os fragmentos as variáveis foram: $X$ sendo a área acumulada em $\mathrm{m}^{2}$ das parcelas ( $250 \mathrm{~m}^{2}$ cada parcela) e $Y$ que o número absoluto de espécies acumuladas. $O$ mesmo procedimento foi realizado para verificar a suficiência amostral em toda a Bacia Hidrográfica do Rio Grande, considerando cada fragmento como uma parcela, porém para a Bacia houve uma modificação na rotina utilizada no momento do sorteio, pois alguns fragmentos possuíam áreas amostrais distintas. Portanto, o número de espécies estimadas para cada um não poderia ser comparado.

\begin{tabular}{|c|c|c|c|c|c|}
\hline \multirow{3}{*}{ A } & \multirow[b]{3}{*}{ Vetor sorteio: } & \multicolumn{4}{|c|}{ Número de parcelas } \\
\hline & & 1 & 2 & $\ldots$ & $\mathrm{n}$ \\
\hline & & 0 & 1 & $\ldots$ & 1 \\
\hline$B$ & & 1 & 2 & $\ldots$ & $\mathrm{n}$ \\
\hline & Vetor sorteio: & 15 & 22 & & 165 \\
\hline & & 1 & 2 & $\ldots$ & $\mathrm{n}$ \\
\hline C & Vetor sorteio: & 1 & 34 & $\ldots$ & 56 \\
\hline D & Vetor área: & 250 & 500 & & $\mathrm{n}$ \\
\hline
\end{tabular}

Figura 4. Modelo de saída de um sorteio, sendo $A$ o vetor de saídas de presença/ausência (da espécie, o B sendo o vetor de saída dos sorteios das parcelas, o C a saída do número acumulado de espécies e $\mathrm{D}$ o tamanho das parcelas em $\mathrm{m}^{2}$.).

Assim, adotou-se um fator de correção (1) para corrigir essas distorções que foi formado pelo inverso do número de parcelas amostradas em cada fragmento, sendo: $n=$ quantidade de parcelas presentes em cada fragmento. No caso envolvendo toda a bacia, adotou-se como estratégia a contagem de fragmentos, para a variável $X$, em detrimento do acumulado em área, como observado nas análises por fragmento. Uma análise por fitofisionomia também foi adotada, porém apenas para a Floresta Estacional Semidecidual que representou 24 fragmentos.

Para finalização da fase dos sorteios, realizou-se o ajuste do modelo quadrático de platô, para definir o ponto de suficiência amostral, caso ocorresse. Segundo Dias (2014), a utilização do modelo quadrático proporciona melhor ajuste comparado ao modelo linear, pois possui mais parâmetros e o seu coeficiente de variação é menor, à medida que se aumenta as unidades amostrais. Diante disso, esse modelo foi adotado para as análises.
A Equação (1) que representou a distribuição de dados foi a equação quadrática:

$$
Y_{i}= \begin{cases}\beta_{0}+\beta_{1} X_{i}+\beta_{2} X_{i}^{2}+\varepsilon_{i} & \text { se } X_{i} \leq X_{0} \\ P+e_{i} & \text { se } X_{i}>X_{0}\end{cases}
$$

Em que: $Y_{i}=$ espécies acumuladas nas parcelas; $X_{i}=$ área acumulada das parcelas em cada fragmento; $X_{0}=$ área onde ocorre o platô; $P=$ quantidade de espécies acumuladas no momento do platô; $\beta_{0}, \beta_{1}$ e $\beta_{2}=$ parâmetros da equação e $e_{i}=$ erro da equação.

O modelo utiliza o método das derivadas para alcançar o platô. Assim, realizando a primeira derivada de $Y$ em relação a $X$ tem-se a equação (2).

$$
\frac{\partial y_{i}}{\partial x_{i}}=\beta_{1}+2\left(\beta_{2}\right) X_{i}
$$

Posteriormente, igualou-se a derivada a zero e resolvemos a equação resultante, ao substituir $\mathrm{X}$ por $\mathrm{X}_{0}$, ponto em que a curva deve ser contínua e suavizada, obtém-se (3).

$$
X_{0}=\frac{-\beta_{1}}{2 \beta_{2}}
$$

Finalmente, substitui-se a resultante de (3) na equação principal (1) chega-se em (4).

$$
\begin{gathered}
Y=P=\beta_{0}+\beta_{1} X_{0}+\beta_{2} X_{0}^{2}=\beta_{0}-\frac{\beta_{1}^{2}}{2 \beta_{2}^{2}}+\frac{\beta_{1}^{2} \beta_{2}}{4 \beta_{2}^{2}} \\
=\beta_{0}-\frac{\beta_{1}^{2}}{4 \beta_{2}}
\end{gathered}
$$

Logo, tem-se que $X_{0}$ e $P$ serão determinados pelos parâmetros da equação. Todas as análises foram implementadas no software R (R CORE TEAM, 2016), sendo adotadas as medidas de avaliação da precisão dos ajustes, como o (Syx\%) erro padrão residual (5) e o $\left(R^{2}\right)$ coeficiente de determinação (6).

$$
\begin{aligned}
& S_{y x \%}=\sqrt{\frac{\sum_{1=1}^{n}\left(y_{j}-\widehat{y_{J}}\right)^{2}}{n-p}} * 100 \\
& R^{2}{ }_{a j .}=1-\left(\frac{S Q r e s}{S Q t}\right) *\left(\frac{n-1}{n-p}\right)
\end{aligned}
$$

\section{RESULTADOS E DISCUSSÃO}

Na Tabela 3 são observados os valores obtidos pelo ajuste dos modelos, envolvendo os coeficientes da 
equação por fragmento, fisionomia e a Bacia, como ainda a área estimada até o platô $\left(X_{0}\right)$, o número de espécies no platô $(\mathrm{P})$. Na Figura 5 é possível verificar os gráficos gerados, após o ajuste do modelo linear de platô, para parte dos 29 fragmentos e toda a BHRG.

$O R^{2}$ variou de 0,97 a 0,99 indicando que a correlação de área amostrada com o número de espécies é significativa e alta. Dessa forma, analisando o $\beta_{0}$ (interceptação da reta no eixo Y) dos modelos (Figura 5), observa-se uma estimativa inicial de espécies elevada para determinados fragmentos, como no fragmento 8 (Lagoa Dourada). Esse por sua vez, já se observa um valor de 36 espécies como expectativa de amostragem já na primeira parcela, demonstrando uma alta riqueza inicial de espécies na área. O que é comprovado pelo grande número de espécies observadas (188).

O local é uma área de transição entre o Cerradão e a Floresta Estacional Semidecidual, indicando assim um maior nicho ecológico de espécies arbóreas. Esses valores corroboram com o estudo como Freitas et al. (2016) amostrando 113 espécies, Reis et al. (2007) que utilizou do modelo de regressão linear de platô para obter a suficiência amostral, encontrando para 7,6 ha um total de 397 espécies arbóreas e o de Franco et al. (2014) que encontrou uma riqueza de 84 espécies em $600 \mathrm{~m}^{2}$, indicando que se houvesse uma maior amostragem seriam encontradas mais espécies.

Tabela 3. Resultados das análises pelo método Boostrap em conjunto com o ajuste dos modelos lineares quadrático de platô para a suficiência amostral da riqueza de espécies da bacia do rio Grande - MG.

\begin{tabular}{|c|c|c|c|c|c|c|c|c|c|c|}
\hline Fragmento & $\begin{array}{c}\text { № de parcelas } \\
\text { amostradas }\end{array}$ & $\begin{array}{c}\text { № de espécies } \\
\text { observadas }\end{array}$ & $\beta_{0}$ & $\beta_{1}$ & $\beta_{2}$ & $X_{0}\left(m^{2}\right)$ & $P(S)$ & $\begin{array}{c}\text { № de parcelas } \\
\text { platô }\end{array}$ & $\mathbf{R}^{2}$ & Sxy \\
\hline 1 & 56 & 165 & 29,05 & 0,01925 & $-7,19 E-07$ & $13.384,1$ & 157,90 & 54 & 0,98 & 4,6 \\
\hline 2 & 50 & 186 & 29,71 & 0,02449 & $-1,00 \mathrm{E}-06$ & $12.204,6$ & 179,15 & 49 & 0,98 & 5,0 \\
\hline 3 & 47 & 188 & 36,15 & 0,02604 & $-1,18 \mathrm{E}-06$ & $11.046,3$ & 179,98 & 44 & 0,98 & 5,8 \\
\hline 4 & 48 & 159 & 33,16 & 0,01925 & $-7,70 \mathrm{E}-07$ & $12.500,5$ & 153,50 & 50 & 0,98 & 4,5 \\
\hline 5 & 38 & 156 & 34,91 & 0,02502 & $-1,36 \mathrm{E}-06$ & $9.227,2$ & 150,34 & 37 & 0,98 & 4,4 \\
\hline 6 & 42 & 147 & 28,11 & 0,02256 & $-1,13 E-06$ & $10.024,4$ & 141,20 & 40 & 0,98 & 4,4 \\
\hline 7 & 45 & 172 & 29,06 & 0,02536 & $-1,18 \mathrm{E}-06$ & $10.782,6$ & 165,77 & 43 & 0,98 & 4,3 \\
\hline 8 & 41 & 152 & 24,60 & 0,02407 & $-1,18 \mathrm{E}-06$ & $10.163,8$ & 146,93 & 41 & 0,99 & 3,5 \\
\hline 9 & 39 & 140 & 21,65 & 0,02251 & $-1,11 \mathrm{E}-06$ & $10.122,3$ & 135,60 & 40 & 0,99 & 3,4 \\
\hline 10 & 27 & 134 & 20,83 & 0,02993 & $-2,03 E-06$ & $7.367,9$ & 131,09 & 29 & 0,99 & 2,9 \\
\hline 11 & 32 & 69 & 22,47 & 0,01150 & $-7,47 \mathrm{E}-07$ & $7.696,3$ & 66,73 & 31 & 0,97 & 1,9 \\
\hline 12 & 29 & 123 & 14,51 & 0,02892 & $-2,00 \mathrm{E}-06$ & $7.242,8$ & 119,22 & 29 & 0,99 & 2,6 \\
\hline 13 & 29 & 117 & 17,72 & 0,02750 & $-1,99 \mathrm{E}-06$ & $6.907,0$ & 112,68 & 28 & 0,98 & 3,0 \\
\hline 14 & 28 & 130 & 15,84 & 0,02780 & $-1,72 \mathrm{E}-06$ & $8.103,6$ & 128,47 & 32 & 0,99 & 2,6 \\
\hline 15 & 29 & 108 & 19,51 & 0,02292 & $-1,55 E-06$ & $7.415,3$ & 104,49 & 30 & 0,98 & 2,8 \\
\hline 16 & 38 & 152 & 27,34 & 0,02679 & $-1,51 \mathrm{E}-06$ & $8.850,2$ & 145,90 & 35 & 0,98 & 4,3 \\
\hline 17 & 30 & 82 & 14,50 & 0,01726 & $-1,15 E-06$ & $7.480,1$ & 79,07 & 30 & 0,98 & 2,2 \\
\hline 18 & 29 & 132 & 16,30 & 0,02916 & $-1,90 \mathrm{E}-06$ & $7.680,7$ & 128,29 & 31 & 0,99 & 2,8 \\
\hline 19 & 28 & 96 & 13,49 & 0,01946 & $-1,13 E-06$ & $8.620,5$ & 97,38 & 34 & 0,99 & 1,8 \\
\hline 20 & 29 & 136 & 15,76 & 0,03004 & $-1,92 \mathrm{E}-06$ & $7.813,6$ & 133,12 & 31 & 0,99 & 2,4 \\
\hline 21 & 29 & 130 & 16,40 & 0,02629 & $-1,52 E-06$ & $8.656,8$ & 130,21 & 35 & 0,99 & 2,3 \\
\hline 22 & 30 & 141 & 21,90 & 0,02970 & $-1,91 \mathrm{E}-06$ & $7.777,9$ & 137,38 & 31 & 0,99 & 2,9 \\
\hline 23 & 30 & 129 & 25,61 & 0,02538 & $-1,62 E-06$ & $7.840,5$ & 125,09 & 31 & 0,98 & 3,4 \\
\hline 24 & 30 & 140 & 14,27 & 0,02925 & $-1,73 E-06$ & $8.468,8$ & 138,13 & 34 & 0,99 & 2,6 \\
\hline 25 & 33 & 101 & 19,74 & 0,01910 & $-1,17 \mathrm{E}-06$ & $8.189,5$ & 97,95 & 33 & 0,98 & 2,4 \\
\hline 26 & 27 & 48 & 9,40 & 0,01212 & $-9,84 E-07$ & $6.157,1$ & 46,70 & 25 & 0,99 & 1,0 \\
\hline 27 & 33 & 73 & 16,91 & 0,01305 & $-7,99 \mathrm{E}-07$ & $8.169,4$ & 70,22 & 33 & 0,98 & 1,9 \\
\hline 28 & 32 & 69 & 10,91 & 0,01357 & $-8,23 E-07$ & $8.244,1$ & 66,85 & 33 & 0,99 & 1,7 \\
\hline 29 & 30 & 107 & 21,25 & 0,02187 & $-1,45 E-06$ & $7.520,1$ & 103,50 & 30 & 0,98 & 2,6 \\
\hline SE & $24 *$ & 625 & 4,30 & 1,18830 & $-2,31 \mathrm{E}-02$ & $21,5^{*}$ & 17,07 & 22 & 0,97 & 0,5 \\
\hline Bacia & 29* & 681 & 4,46 & 1,16134 & $-2,77 \mathrm{E}-02$ & $25,1863^{*}$ & 19,08 & 26 & 0,98 & 0,6 \\
\hline
\end{tabular}

$\beta_{1}, \beta_{2}$ e $\beta_{3} ; X_{0}, P=$ parâmetros do modelo, $R^{2}=$ coeficiente de determinação, Sxy = erro padrão residual e SE -= Floresta Estacional Semidecidual $\mathrm{e}^{*}=$ número de fragmentos amostrados. 
(A) Fragmento 1

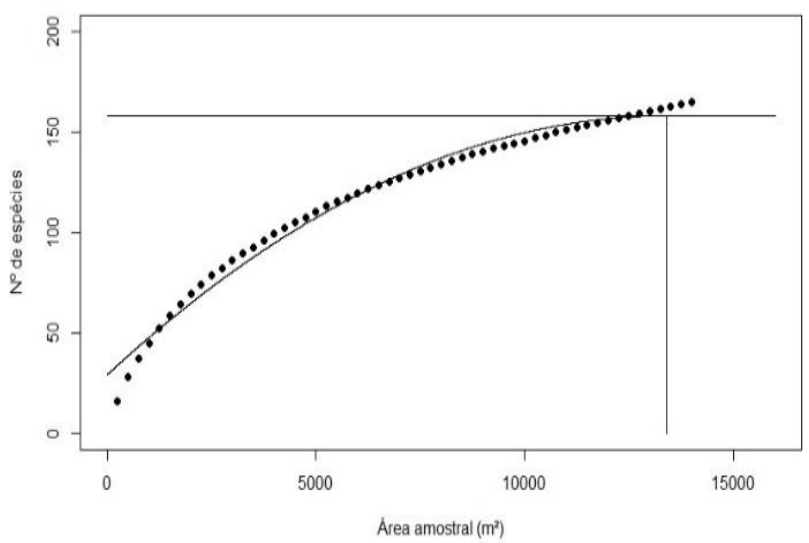

(C) Fragmento 8

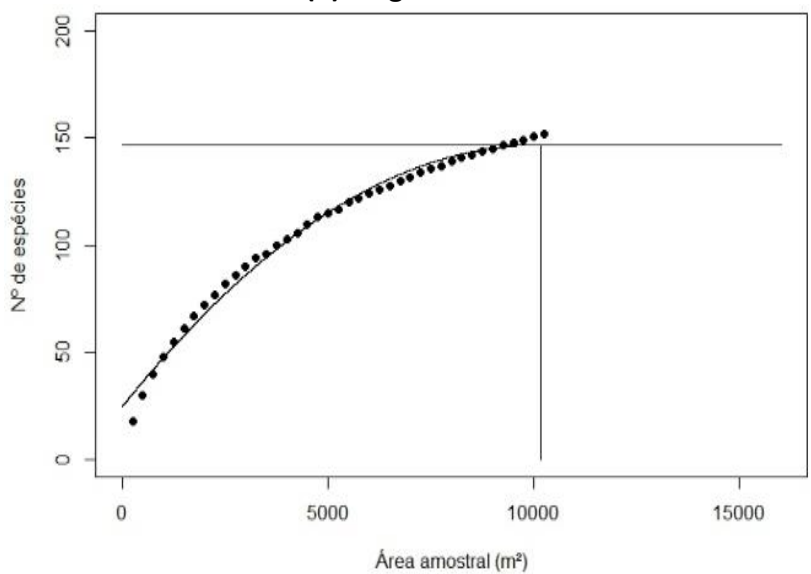

(B) Fragmento 4

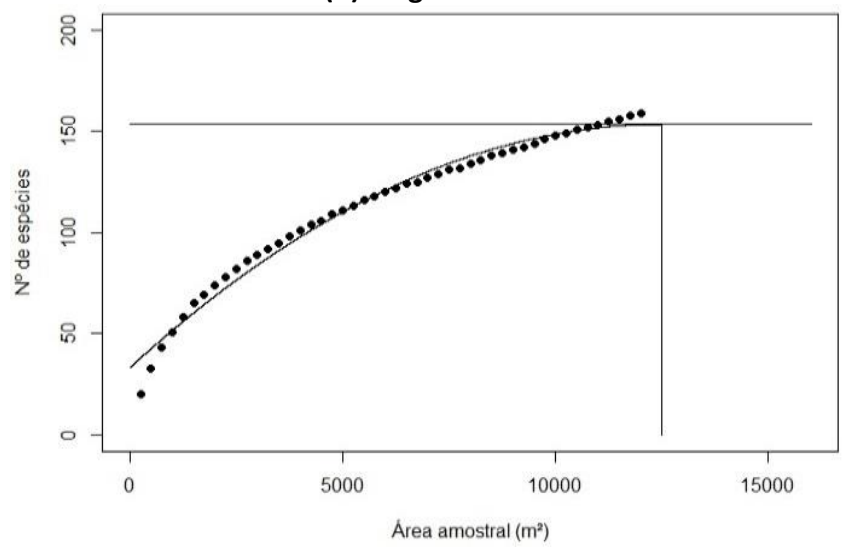

(D) Bacia hidrográfica

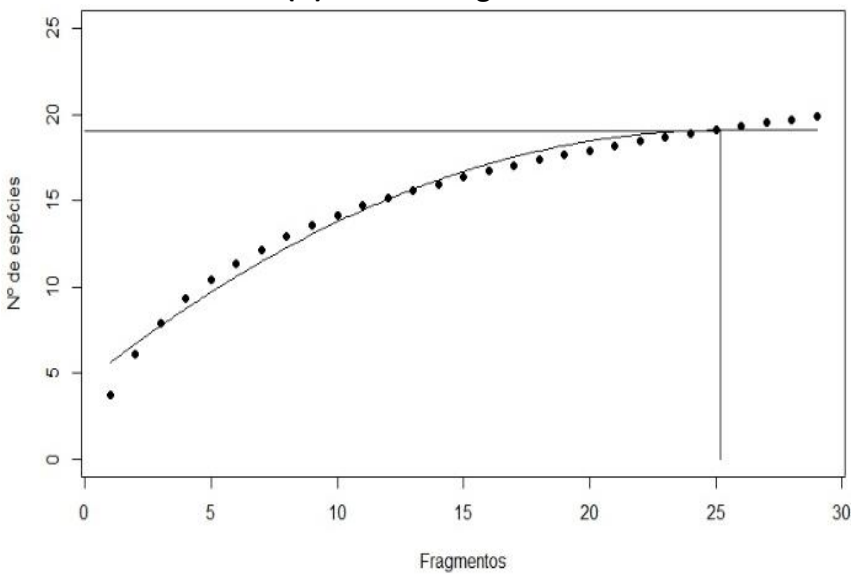

Figura 5. Avaliação gráfica da formação do platô para os ambientes em estudo localizados na BHRG em Minas Gerais.

Em outras áreas, como o fragmento 26 (Frutal) observase um $\beta_{0}$ menor $(9,4)$ e um reduzido número de espécies (48), indicando baixa riqueza de espécies na área. Isso pode ter ocorrido devido ao uso do solo em áreas adjacentes, como as culturas agrícolas. Esse problema é apresentado por Silva et al. (2016), que detectaram uma redução do número de espécies de um fragmento de Floresta Estacional Semidecidual, sendo 132 (2010) e 129 (2015) e, Miguel et al. (2016) que encontraram 82 espécies.

Na Floresta Ombrófila presente no estudo, observou-se apenas 69 espécies. Dionisio et al. (2016) amostraram apenas 45 espécies em 0,54 ha na mesma fitofisionomia. Condé \& Tonini (2013), amostraram 9 ha e encontraram 165 espécies arbóreas, sendo 40 consideradas espécies raras ou localmente raras. Esses valores indicam que se a amostragem nessa fitofisionomia tivesse sido maior, ela poderia apresentar uma maior riqueza de espécies, mas este valor torna-se dependente do estágio de conservação local

Verificou-se pelo modelo de platô, que dos 29 fragmentos amostrados, 13 não atingiram a área amostral suficiente. Por outro lado, um total de 10 fragmentos apresentaram uma maior amostragem, ou seja, foi lançando mais do que o necessário para atingir a suficiência amostral. Houve ainda, 6 fragmentos que tiveram uma amostragem exata, ou seja, o número de parcelas lançadas foi exatamente o solicitado para captar a variação da riqueza local. Para toda a Bacia a amostragem foi suficiente, onde deveriam ser amostrados 26 fragmentos e foram 29.

Pode-se averiguar que apesar de alguns fragmentos não terem alcançado a suficiência amostral em área, eles se mantiveram muito próximos da quantidade de parcelas para o platô, variando em média 2,46. Utilizando o modelo de regressão linear de platô, Gomide et al., (2006) também atingiram a suficiência amostral em seu estudo na Bacia do Rio São Francisco onde a amostragem foi maior que o necessário em todos os 20 fragmentos.

Outro estudo em modelo de platô foi realizado por Miguel et al. (2016) em que foram amostrados 2,16 ha de uma área de Cerradão encontrando 82 espécies arbóreas, mas verificou-se que a suficiência amostral seria alcançada com 1,6 ha e que com esse valor seria possível amostrar 79 espécies arbóreas atingindo $90 \%$ das espécies amostradas que, segundo Pires-O'Brien \& O’Brien (1995) é a amostragem mínima suficiente para representar a comunidade.

A suficiência amostral da Floresta Estacional 
Semidecidual (FES) e da BHRG foram alcançadas, segundo o modelo quadrático utilizado, sendo o ideal para estudo em grandes áreas. Considerando a FES, dos 24 fragmentos amostrados eram necessários apenas 22 para atingir a suficiência amostral, atingindo assim 17,07 espécies e, para a BHRG dos 29 fragmentos eram necessários 27, com 19,08 espécies. Esse valor de espécies $(17,07)$ é, assim como o da Bacia $(19,08)$, um valor ponderado devido aos tamanhos diferentes dos fragmentos, sendo assim difícil a sua comparação com outros estudos.
$\mathrm{Na}$ Tabela 3 observa-se a comparação entre a estimativa de espécies encontradas no platô, juntamente com o seu intervalo de confiança, ou seja, a variação que pode ocorrer na estimativa do modelo, o número de espécies observadas quando foi realizada a amostragem e a estimativa do total de espécies pelo modelo, quando se substituiu o XO pela área amostrada de cada fragmento. $\mathrm{O}$ valor total de espécies estimadas pelo modelo mostrou que apesar de não alcançar a área estimada no platô, todos os fragmentos conseguiram alcançar mais espécies que o modelo poderia estimar.

Tabela 3. Avaliação do erro padrão residual (Erro), estimativas de espécies no momento de platô (P) e seu intervalo de confiança (P-Erro e P+Erro); número de espécies observadas; número de espécies estimadas com a área amostral real pelo modelo e o erro $(E)$ entre o número de espécies estimadas pelo modelo utilizando a área real; número de espécies observadas.

\begin{tabular}{|c|c|c|c|c|c|c|c|c|c|}
\hline $\mathbf{F}$ & $\begin{array}{c}\text { № de parcelas } \\
\text { amostradas }\end{array}$ & $\begin{array}{c}\text { Área amostrada } \\
\left(\mathrm{m}^{2}\right)\end{array}$ & P-Erro & $\mathbf{P}$ & P+Erro & Erro & $\begin{array}{c}\text { № de espécies } \\
\text { observadas }\end{array}$ & $\begin{array}{c}\text { № de espécies } \\
\text { estimadas }\end{array}$ & $E$ \\
\hline 1 & 56 & 14.000 & 153,29 & 157,90 & 162,51 & 4,6 & 165 & 158 & 7 \\
\hline 2 & 50 & 12.500 & 174,10 & 179,15 & 184,21 & 5,0 & 186 & 179 & 7 \\
\hline 3 & 47 & 11.750 & 174,16 & 179,98 & 185,79 & 5,8 & 188 & 179 & 9 \\
\hline 4 & 48 & 12.000 & 148,98 & 153,50 & 158,02 & 4,5 & 159 & 153 & 6 \\
\hline 5 & 38 & 9.500 & 145,92 & 150,34 & 154,77 & 4,4 & 156 & 150 & 6 \\
\hline 6 & 42 & 10.500 & 136,75 & 141,20 & 145,65 & 4,4 & 147 & 141 & 6 \\
\hline 7 & 45 & 11.250 & 161,42 & 165,77 & 170,11 & 4,3 & 172 & 166 & 6 \\
\hline 8 & 41 & 10.250 & 143,39 & 146,93 & 150,47 & 3,5 & 152 & 147 & 5 \\
\hline 9 & 39 & 9.750 & 132,18 & 135,60 & 139,01 & 3,4 & 140 & 135 & 5 \\
\hline 11 & 32 & 8.000 & 64,73 & 66,73 & 68,72 & 1,9 & 69 & 67 & 2 \\
\hline 12 & 29 & 7.250 & 116,56 & 119,22 & 121,89 & 2,6 & 123 & 119 & 4 \\
\hline 13 & 29 & 7.250 & 109,58 & 112,68 & 115,77 & 3,0 & 117 & 112 & 5 \\
\hline 14 & 28 & 7.000 & 125,79 & 128,47 & 131,15 & 2,6 & 130 & 126 & 4 \\
\hline 15 & 29 & 7.250 & 101,67 & 104,49 & 107,31 & 2,8 & 108 & 104 & 4 \\
\hline 16 & 38 & 9.500 & 141,54 & 145,90 & 150,27 & 4,3 & 152 & 145 & 7 \\
\hline 17 & 30 & 7.500 & 76,85 & 79,07 & 81,29 & 2,2 & 82 & 79 & 3 \\
\hline 18 & 29 & 7.250 & 125,48 & 128,29 & 131,10 & 2,8 & 132 & 128 & 4 \\
\hline 19 & 28 & 7.000 & 95,57 & 97,38 & 99,20 & 1,8 & 96 & 94 & 2 \\
\hline 20 & 29 & 7.250 & 130,62 & 133,12 & 135,61 & 2,4 & 136 & 133 & 3 \\
\hline 21 & 29 & 7.250 & 127,85 & 130,21 & 132,57 & 2,3 & 130 & 127 & 3 \\
\hline 22 & 30 & 7.500 & 134,45 & 137,38 & 140,32 & 2,9 & 141 & 137 & 4 \\
\hline 23 & 30 & 7.500 & 121,67 & 125,09 & 128,51 & 3,4 & 129 & 125 & 4 \\
\hline 24 & 30 & 7.500 & 135,53 & 138,13 & 140,73 & 2,6 & 140 & 137 & 3 \\
\hline 25 & 33 & 8.250 & 95,51 & 97,95 & 100,38 & 2,4 & 101 & 98 & 3 \\
\hline 26 & 27 & 6.750 & 45,67 & 46,70 & 47,72 & 1,0 & 48 & 46 & 2 \\
\hline 27 & 33 & 8.250 & 68,23 & 70,22 & 72,22 & 1,9 & 73 & 70 & 3 \\
\hline 28 & 32 & 8.000 & 65,15 & 66,85 & 68,55 & 1,7 & 69 & 67 & 2 \\
\hline 29 & 30 & 7.500 & 100,85 & 103,50 & 106,15 & 2,6 & 107 & 103 & 4 \\
\hline
\end{tabular}




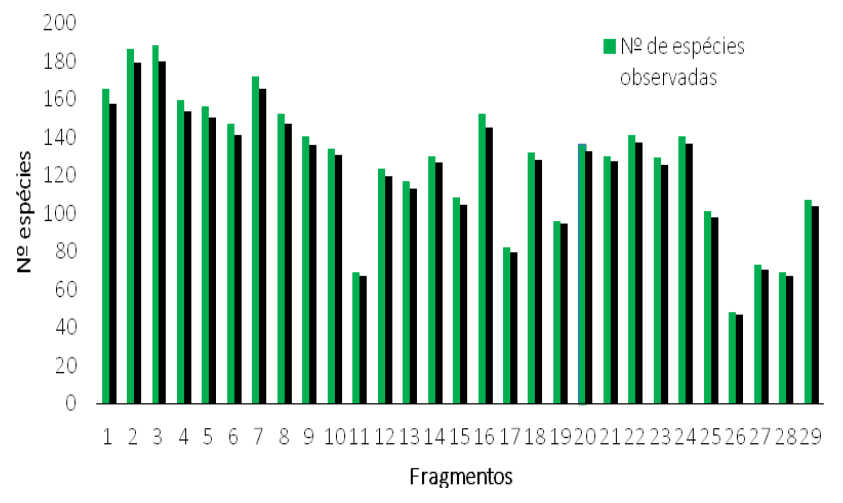

Figura 6. Diferença entre o número de espécies observadas e o número de espécies estimadas pelo modelo para cada um dos fragmentos amostrados.

Na Figura 6 mostra-se a diferença entre o número de espécies totais observadas por fragmento e o número de espécies totais estimadas pelo modelo, demonstrando que o modelo subestima esse valor, pois o real encontrado nos fragmentos sempre foi maior que a quantidade estimada pelo modelo, variando de 2 a 9 espécies e, o erro médio foi de 4 espécies. Vale ressaltar que o objetivo do modelo não é encontrar o total e sim o platô, podendo ser por isso, a sua subestimativa.

Os valores de espécies estimadas totais, parte dos fragmentos estão dentro do intervalo de confiança dos valores de espécies estimadas no platô, isso acontece porque o modelo estimou um platô muito próximo do que se foi amostrado. Com exceção do fragmento 19, todos apresentaram-se dentro do intervalo de confiança nesse, onde o total de espécies estimadas foram foi 94 e o intervalo de confiança do estimado para o platô foi de 95,27 a 99,20. Isso pode ser explicado por ele ser o fragmento que mais se distanciou do platô, com um déficit de 6 parcelas.

Desta forma, cabe lembrar que a identificação botânica é de extrema importância para estudos como esse. Logo, para a Bacia Hidrográfica, como um todo, a suficiência amostral foi atingida, podendo esse estudo ser utilizado para a indicação de espécies destinadas a recuperação de áreas degradadas, por exemplo.

\section{CONCLUSÃO}

A partir das avaliações aqui realizadas, constatou-se que, pelo modelo quadrático de resposta em platô, a amostragem realizada foi suficiente para toda a Bacia Hidrográfica do Rio Grande. A mesma tendência foi observada para a fitofisionomia Estacional Semidecidual, que também atingiu a suficiência amostral em 22 dos 24 fragmentos amostrados. Já em nível de fragmento, a suficiência amostral foi atingida em $55 \%$ dos fragmentos amostrados (16 de 29).

\section{REFERÊNCIAS}

AUGUSTYNCZIK, A.L.D. et al. Avaliação do tamanho de parcelas e de intensidade de amostragem em inventários florestais. Scientia Forestalis, v.41, n.99, p.361-368, 2013.

BRACK, P. et al. Levantamento preliminar de espécies frutíferas de árvores e arbustos nativos com uso atual ou potencial do Rio Grande do Sul. Revista Brasileira de Agroecologia, v.2, n.1, p.1769-1772, 2007.

BONETES, L. Tamanho de parcelas e intensidade amostral para estimar o estoque e índices fitossociológicos em uma Floresta Ombrófila Mista. 2008. 111p. (Dissertação de mestrado).

CONDÉ, T.M.; TONINI, H. Fitossociologia de uma Floresta Ombrófila Densa na Amazônia Setentrional, Roraima, Brasil. Acta Amazonica, v.43, n.3, p.247-260, 2013.

FREITAS, W.K. et al. Estrutura horizontal de um trecho da Floresta Decidual da região oeste de Santa Catarina, Brasil Horizontal structure of a stretch of Seasonal Dry Forest of western Santa Catarina State, Brazil. Ambiência, v.12, n.1, p.217-232, 2016.

DIAS, T.C. Forma e tamanho ótimos de parcelas experimentais de Eucalipto clonal em sistemas de integração lavoura-pecuáriafloresta. 2014. 115p. (Dissertação de mestrado).

DIONISIO, L.F.S. et al. Importância fitossociológica de um fragmento de floresta ombrófila densa no estado de Roraima, Brasil. Revista Agro@mbiente On-Line, v.10, n.3, p.243-252, 2016.

FRANCEZ, L.M.B. et al. Mudanças ocorridas na composição florística em decorrência da exploração florestal em uma área de floresta de Terra Firme na região de Paragominas, PA. Acta Amazonica, v.37, n.2, p.219-228, 2007.

FRANCO, B.K.S. et al. Estrato de regeneração natural de um trecho de floresta estacional semidecidual, Viçosa, MG. Revista Árvore, v.8, n.1, p.31-40, 2014.

DIONISIO, L.F.S. et al. Importância fitossociológica de um fragmento de floresta ombrófila densa no estado de Roraima, Brasil. Revista Agro@mbiente On-Line, v.10, n.3, p.243-252, 2016.

GOMIDE, L.R. et al. Análise da diversidade e similaridade de fragmentos florestais nativos na bacia do rio São Francisco, em Minas Gerais. Ciência Florestal, v.16, n.2, p.127-144, 2006.

SAPORETTI JUNIOR, A.W.S. et al. Estrutura e grupos ecológicos de um trecho de floresta estacional semidecidual montana no município de Dom Silvério, Minas Gerais. Revista Interface, n.12, p.55-69, 2017.

LORENZI, H. Árvores Brasileiras: manual de identificação e cultivo de plantas arbóreas nativas do Brasil. 3.ed. São Paulo: Instituto Plantarum, 2009. 
MIGUEL, E.P. et al. Floristic-structural characterization and successional group of tree species in the Cerrado biome of Tocantins state, Brazil. Revista Caatinga, v.29, n.2, p.393-404, 2016.

MORENO, M.R. et al. Estrutura e composição florística do estrato arbóreo em duas zonas altitudinais na Mata Atlântica de encosta da região do Imbe, RJ. Acta Botanica Brasilica, v.17, n.3, p.371386, 2003.

MORO, M.F.; MARTINS, F.R. Métodos de levantamento do componente arbóreo-arbustivo. v.1. Viçosa: UFV, 2011.

DIAS NETO, O.C.D. et al. Estrutura fitossociológica e grupos ecológicos em fragmento de floresta estacional semidecidual, Uberaba, Minas Gerais, Brasil. Rodriguésia, v.60, n.4, p.10871100, 2009.

OLIVEIRA, V.A. et al. Land-use change impacts on the hidrology of the upper Grande River Basin, Brazil. Cerne, v.24, n.4, p.334-343, 2019.

OLIVEIRA FILHO, A.T.; SCOLFORO, J.R. Compilação e caracterização das espécies arbóreas da flora nativa de Minas Gerais. Espécies Arbóreas da Flora Nativa. Lavras: Editora UFLA, 2008.

PIRES-O'BRIEN, M.J.; O'BRIEN, C.M. Ecologia e modelamento de florestas tropicais. v.1. Belém: FCAP, 1995.

R DEVELOPMENT CORE TEAM. R: a language and environment for statistical computing. Vienna: R Foundation for Statistical Computing, 2016.

REIS, H. et al. Análise da composição florística, diversidade e similaridade de fragmentos de mata atlântica em Minas Gerais. Cerne, v.13, n.3, p.280-290, 2007.

SCHILLING, A.C; BATISTA, J.L.F. Curva de acumulação de espécies e suficiência amostral em florestas tropicais. Revista Brasileira de Botânica, v.31, n.1, p.179-187, 2008.

SCOLFORO, J.R.S.; OLIVEIRA, A.D. de; CARVALHO, L.M.T. de. Zoneamento ecológico-econômico do Estado de Minas Gerais: componente socioeconômico. Lavras: UFLA, 2008.

SILVA, A.B. et al. Levantamento da biodiversidade de arbóreas em fragmento florestal na região Sul de Minas Gerais. Revista Agrogeoambiental, v.8, n.4, p.47-60, 2016.

SILVA, C.P.C. et al. Composição florística na floresta Estacional Semidecidual e floresta Ombrófila. Inventário Florestal de Minas Gerais. 22. ed. Lavras: Ed. UFLA, 2008.

SOUZA, D.R. et al. Análise estrutural em Floresta Ombrófila Densa de terra firme não explorada, Amazônia Oriental. Revista Árvore, v.30, n.1, p.75-87, 2006.

THORNTHWAITE, C.W.; MATHER, J.C. The water balance. Centeron: Drexel Institute of Technology, 1955.

URQUHART, G.R. The Neotropical Rainforests. Earth Systems and Environmental Sciences. Reference Module, 2019. 